\title{
Guselkumab demonstrated an independent treatment effect in reducing fatigue after adjustment for clinical response-results from two phase 3 clinical trials of 1120 patients with active psoriatic arthritis
}

Proton Rahman', Philip J. Mease ${ }^{2}$, Philip S. Helliwell ${ }^{3}$, Atul Deodhar ${ }^{4}$, Laure Gossec ${ }^{5,6}$, Arthur Kavanaugh? Alexa P. Kollmeier ${ }^{8}$, Elizabeth C. Hsia ${ }^{9}{ }^{10}$, Bei Zhou' ${ }^{9}$, Xiwu Lin' ${ }^{9}$, May Shawi ${ }^{11}$, Chetan S. Karyekar ${ }^{11}$ and Chenglong $\operatorname{Han}^{9^{*}}$ (D)

\begin{abstract}
Background: The interleukin-23p19-subunit inhibitor guselkumab effectively treats signs and symptoms of psoriatic arthritis (PsA). We evaluated the effect of guselkumab on fatigue.

Methods: Across two phase 3 trials of guselkumab (DISCOVER-1, DISCOVER-2), patients with active PsA despite standard therapy were randomized to subcutaneous injections of guselkumab $100 \mathrm{mg}$ every 4 weeks (Q4W, N = 373); guselkumab $100 \mathrm{mg}$ at week 0, week 4, and then Q8W ( $N=375)$; or placebo $(N=372)$ through week 24, after which patients in the placebo group crossed over to guselkumab Q4W. Fatigue was measured as a secondary endpoint using the Functional Assessment of Chronic Illness Therapy (FACIT)-Fatigue instrument (range 0-52, higher scores indicate less fatigue). Least-squares mean changes in FACIT-Fatigue scores were compared between treatments using a mixedeffect model for repeated measures. Mediation analysis was used to adjust for indirect effects on fatigue deriving from improvement in other outcomes, including $\geq 20 \%$ improvement in American College of Rheumatology criteria (ACR20; prespecified), minimal disease activity (MDA; post hoc), or C-reactive protein (CRP; post hoc).
\end{abstract}

Results: Baseline mean (SD) FACIT-Fatigue scores in DISCOVER-1 $(N=381)$ and DISCOVER-2 $(N=739)$, ranging from 29.1 (9.5) to 31.4 (10.1), indicated substantial levels of fatigue relative to the United States general population (43.6 [9.4]). Across studies, mean improvements, and proportions of patients with $\geq 4$ point improvements, in FACIT-Fatigue scores at week 24 with guselkumab Q4W and Q8W (5.6-7.6 and 54$63 \%$, respectively) were larger vs placebo (2.2-3.6 and 35-46\%). Improvement in FACIT-Fatigue scores with guselkumab was sustained from week 24 to week 52, with moderate-to-large effect sizes (Cohen's $d=$ $0.52-0.81$ at week $24 ; 0.66-0.91$ at week 52 ). Mediation analyses demonstrated that substantial proportions

\footnotetext{
* Correspondence: CHan3@its.jnj.com

${ }^{9}$ Janssen Research \& Development, LLC, Spring House, PA 19436, USA

Full list of author information is available at the end of the article
}

(c) The Author(s). 2021 Open Access This article is licensed under a Creative Commons Attribution 4.0 International License, which permits use, sharing, adaptation, distribution and reproduction in any medium or format, as long as you give appropriate credit to the original author(s) and the source, provide a link to the Creative Commons licence, and indicate if changes were made. The images or other third party material in this article are included in the article's Creative Commons. licence, unless indicated otherwise in a credit line to the material. If material is not included in the article's Creative Commons licence and your intended use is not permitted by statutory regulation or exceeds the permitted use, you will need to obtain permission directly from the copyright holder. To view a copy of this licence, visit http://creativecommons.org/licenses/by/4.0/. The Creative Commons Public Domain Dedication waiver (http://creativecommons.org/publicdomain/zero/1.0/) applies to the data made available in this article, unless otherwise stated in a credit line to the data. 
of the effects of guselkumab vs placebo on fatigue were direct effect, after adjusting for achievement of ACR20 (Q4W 69-70\%, Q8W 12-36\% direct effect) or MDA (72-92\% across dosing regimens) response or for change in serum CRP concentrations (82-88\% across dosing regimens).

Conclusions: In patients with active PsA, guselkumab $100 \mathrm{mg}$ Q4W or Q8W led to clinically meaningful and sustained improvements in fatigue through 1 year. A substantial portion of the improvement in FACITFatigue scores induced by guselkumab was independent of effects on the achievement of other select outcomes.

Trial registration: Name of the registry: ClinicalTrials.gov

Trial registrations: DISCOVER-1, NCT03162796; DISCOVER-2, NCT03158285

Date of registration: DISCOVER-1, May 22, 2017; DISCOVER-2, May 18, 2017

URLS of the trial registry record:

DISCOVER-1, https://clinicaltrials.gov/ct2/show/NCT03162796?term=NCT03162796\&draw=1\&rank=1 DISCOVER-2, https:/clinicaltrials.gov/ct2/show/NCT03158285?term=NCT03158285\&draw=2\&rank=1

Keywords: Interleukin-23, p19 subunit, Biologic, Fatigue, Psoriatic arthritis, Patient-reported outcome, Mediation analysis

\section{Background}

Psoriatic arthritis (PsA) is a chronic inflammatory arthropathy with diverse manifestations. It can affect peripheral and axial joints, be accompanied by enthesitis and/or dactylitis, and associate with psoriasis [1]. Fatigue is commonly experienced by individuals with chronic inflammatory diseases such as PsA and is associated with disease activity, pain, sleep disturbances, and depression $[2,3]$. Fatigue is defined as a feeling of exhaustion, with decreased capacity for physical and mental work [4]. It includes a range of experiences, from tiredness to exhaustion, that can interfere with normal daily function and reduce health-related quality of life (HRQoL). Patients with PsA consider fatigue as one of their most important symptoms [5, 6], and moderate-to-severe fatigue is reported by up to half of PsA patients [5-9]. The importance of fatigue as a treatment target is highlighted in the European League Against Rheumatism (EULAR) recommendations for the management of PsA [10], and it has been added to the core domains for PsA assessment in clinical studies by OMERACT [11].

The mechanism underlying fatigue is complex and undefined, and it can involve physiological, psychological, and social aspects [4]. Signs and symptoms of PsA are effectively treated with biologics that block specific cytokines and reduce inflammation. Improvement of fatigue has also been evaluated in biologic clinical trials, with variable measurement tools and results [12-14]. In a recent report of a population-based cohort study, substantial fatigue remained following tumor necrosis factorinhibitor (TNFi) therapy [15]. To develop new therapies for effective treatment of fatigue in patients with PsA, information is needed on the causality of their fatigue, as well as efficacy associated with distinct mechanisms of action.
Guselkumab (Janssen Biotech, Horsham, PA, USA), a high-affinity, human monoclonal antibody specific to the interleukin (IL)-23p19-subunit, is approved to treat patients with moderate-to-severe psoriasis and active PsA [16]. In DISCOVER-1 and DISCOVER-2, the pivotal phase 3 studies evaluating guselkumab in patients with PsA, guselkumab effectively treated the diverse manifestations of PsA, including joint signs and symptoms, physical function, skin disease, enthesitis, dactylitis, and HRQoL, with maintenance of improvements through 1 year [17-19]. We now report the efficacy of guselkumab in treating the fatigue of PsA, using a validated patientreported outcome (PRO) instrument, the Functional Assessment of Chronic Illness Therapy-Fatigue (FACIT-Fatigue) [20, 21], through 1 year of DISCOVER-1 and DISCOVER-2. Employing mediation analysis, we also evaluated the direct effect of guselkumab on fatigue, defined as the change in FACIT-Fatigue score in patients treated with guselkumab after adjustment for select clinical outcomes, including achievement of $\geq 20 \%$ improvement in the American College of Rheumatology (ACR20) or minimal disease activity (MDA) responses or changes in serum C-reactive protein (CRP) concentrations.

\section{Methods}

Patients and study designs

DISCOVER-1 [17] and DISCOVER-2 [18] were phase 3, randomized, placebo-controlled trials of guselkumab in patients with PsA, with similar study designs. Both trials enrolled patients with active PsA, diagnosed according to the Classification Criteria for Psoriatic Arthritis (CASPAR) [22], who did not respond to or were intolerant of non-biologic disease-modifying anti-rheumatic 
drugs (DMARDs), apremilast, and/or non-steroidal antiinflammatory drugs. Active PsA was defined as $\geq 3$ tender and $\geq 3$ swollen joints and serum CRP concentrations $\geq 0.3 \mathrm{mg} / \mathrm{dL}$ in DISCOVER- 1 and as $\geq 5$ tender and $\geq 5$ swollen joints and serum CRP $\geq 0.6 \mathrm{mg} / \mathrm{dL}$ in DISCOVER-2. Prior treatment with $\leq 2$ TNFi was permitted, but limited to approximately $30 \%$ of the study population, in DISCOVER-1 [17]. All DISCOVER-2 patients were biologic-naïve [18].

In both studies, patients were randomized to receive subcutaneous injections of guselkumab $100 \mathrm{mg}$ at week 0 then every 4 weeks (Q4W), guselkumab $100 \mathrm{mg}$ at weeks 0 and 4 then every 8 weeks $(\mathrm{Q} 8 \mathrm{~W})$ with placebo at alternating 4-week intervals, or placebo Q4W. Patients in the placebo group crossed over to guselkumab $100 \mathrm{mg}$ Q4W at week 24. Treatment in DISCOVER-1 continued through week 48 and in DISCOVER-2 through week 100 .

\section{Assessment of fatigue}

The FACIT-Fatigue instrument is a 13 -item PRO validated to measure fatigue and its impact on daily activities and function during the previous week in patients with PsA [20, 21]. Total FACIT-Fatigue scores range from 0 to 52, with higher scores indicating less fatigue. Clinically meaningful improvement in the FACITFatigue score is defined as a $\geq 4$-point increase [21]. The mean (standard deviation [SD]) FACIT-Fatigue score, derived from limited studies in the general United States (US) population, has been reported as 43.6 (9.4) [23].

\section{Statistical methods}

Treatment failure rules were applied to analyses of FACI T-Fatigue scores through week $24[17,18]$ and postweek 24 [19] as previously described. Changes from baseline through week 24 (placebo-controlled period) in FACIT-Fatigue scores were assessed using a mixedeffect model for repeated measures (MMRM). The MMRM adjusted for baseline FACIT-Fatigue scores and randomization stratification factors (baseline use of nonbiologic DMARDs [yes/no] and prior use of TNFi [yes/ no] for DISCOVER-1; baseline use of non-biologic DMARDs [yes/no] and baseline CRP $[>2.0 / \leq 2.0 \mathrm{mg} / \mathrm{dL}]$ for DISCOVER-2). Resulting least-squares (LS) mean changes and surrounding 95\% confidence intervals (CIs) are reported. $\mathrm{P}$ values were not adjusted for multiplicity of testing.

The effect size of observed changes from baseline in FACIT-Fatigue scores at weeks 24 and 52 was calculated using Cohen's method, by dividing the change in FACI T-Fatigue score from baseline by the SD of baseline scores. Effect sizes of $0.20,0.50$, and 0.80 indicate small, moderate, and large effects, respectively [24].
The proportions of patients achieving clinically meaningful improvement ( $\geq 4$-point increase) in the FACITFatigue score [21] at week 24 were compared between each guselkumab group and placebo using a CochranMantel-Haenszel test (with stratification as described above); 95\% CIs were derived from Wald statistics. P values were not adjusted for multiplicity of testing.

Modified cumulative distribution curves [25] were generated to show the proportions of patients achieving various levels of improvement in the FACIT-Fatigue score from $\geq 0$ to $\geq 20$ at week 24 by treatment group.

Mediation analysis [26, 27], as depicted in Fig. 1, was conducted to estimate the proportion of direct treatment effect on FACIT-Fatigue scores after adjusting for the indirect effect mediated by improvement in other selected clinical outcomes. Outcomes assessed included achievement of ACR20, as predefined, and achievement of the MDA composite endpoint [28] or changes in serum CRP concentrations, as determined post hoc. The mediation analyses employed linear regression and logistic regression models with bootstrapping to determine 95\% CIs. Baseline covariates included age, sex, body mass index, baseline FACIT-Fatigue score, CRP (mg/ $\mathrm{dL}$ ), PsA duration (years), physician's global assessment of disease $(0-10-\mathrm{cm}$ visual analog scale [VAS]), patient's global assessment of arthritis (0-10-cm VAS), Health Assessment Questionnaire-Disability Index score (0-3), patient's assessment of pain (0-10-cm VAS), swollen joint count (0-66), and tender joint count (0-68).

\section{Results}

Patient disposition and baseline characteristics

Of the patients enrolled in DISCOVER-1 $(N=381)$ and DISCOVER-2 $(N=739), 91 \%$ and $93 \%$, respectively, completed treatment through 1 year. Patients randomized at baseline (guselkumab $100 \mathrm{mg}$ Q4W, $N=373$; guselkumab $100 \mathrm{mg}$ Q8W, $N=375$; placebo, $N=372$ ) had a mean (SD) age of 46.6 (11.7), mean (SD) PsA disease duration of 5.9 (6.1) years, and substantial disease burden (Table 1). Within each study, baseline characteristics were generally consistent across randomized treatment groups. DISCOVER-2 participants had numerically higher levels of systemic inflammation and swollen and tender joint counts, per study design, and also demonstrated more skin psoriasis involvement. Mean (SD) baseline FACIT-Fatigue scores, which were consistent across randomized treatment groups and between the DISCOVER-1 and DISCOVER-2 populations, ranged from 29.1 (9.5) to 31.4 (10.1).

\section{Changes in FACIT-Fatigue scores over time through week 52}

At week 24, mean increases (improvements) in FACITFatigue scores were 5.8 and 5.6 in the guselkumab Q4W 


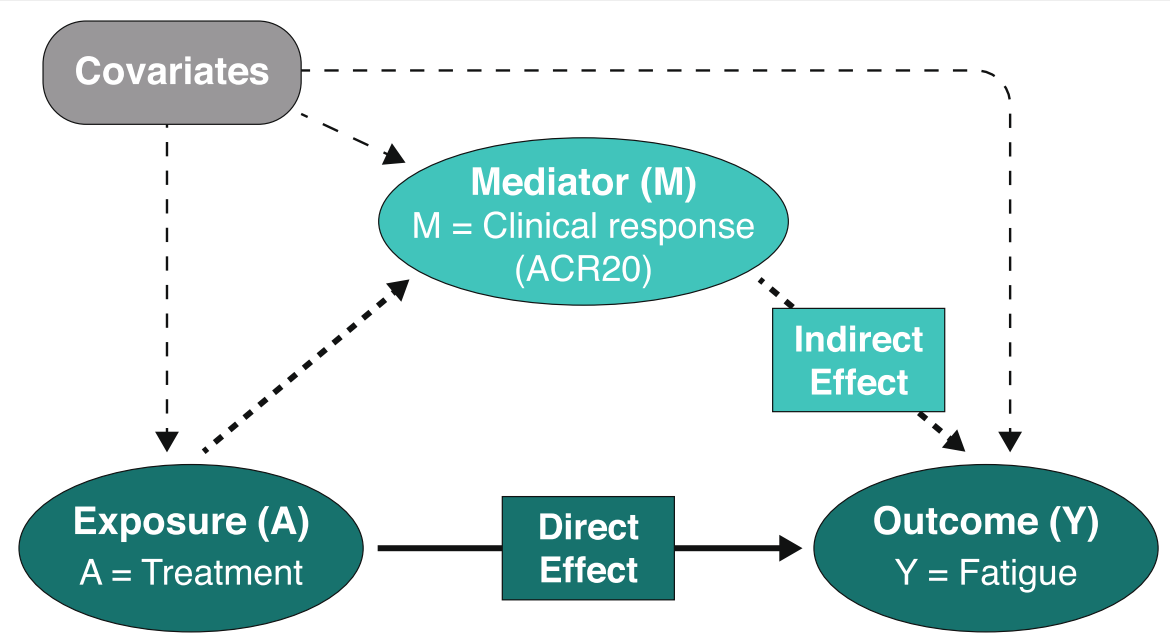

Fig. 1 Mediation analysis. Direct effect = treatment effect on outcome independent of the effect on the mediator; indirect effect = treatment effect on outcome that is attributed to its effect on the mediator. ACR20, $\geq 20 \%$ improvement in American College of Rheumatology criteria

Table 1 Baseline characteristics

\begin{tabular}{|c|c|c|c|c|c|c|}
\hline & \multicolumn{3}{|l|}{ DISCOVER-1 } & \multicolumn{3}{|l|}{ DISCOVER-2 } \\
\hline & $\begin{array}{l}\text { Guselkumab } \\
100 \mathrm{mg} \text { Q4W }\end{array}$ & $\begin{array}{l}\text { Guselkumab } \\
100 \text { mg Q8W }\end{array}$ & Placebo & $\begin{array}{l}\text { Guselkumab } \\
100 \text { mg Q4W }\end{array}$ & $\begin{array}{l}\text { Guselkumab } \\
100 \text { mg Q8W }\end{array}$ & Placebo \\
\hline N & 128 & 127 & 126 & 245 & 248 & 246 \\
\hline Age (years) & $47(12)$ & $49(12)$ & $49(11)$ & $46(12)$ & $45(12)$ & $46(12)$ \\
\hline Male, n (\%) & $66(52 \%)$ & $68(54 \%)$ & $61(48 \%)$ & $142(58 \%)$ & $129(52 \%)$ & $117(48 \%)$ \\
\hline BMI $\left(\mathrm{kg} / \mathrm{m}^{2}\right)$ & $29.9(5.5)$ & $29.9(6.4)$ & $29.6(5.7)$ & $29.1(5.9)$ & $28.7(6.3)$ & $29.0(6.4)$ \\
\hline PsA disease duration (years) & $6.6(6.3)$ & $6.4(5.9)$ & $7.2(7.6)$ & $5.5(5.9)$ & $5.1(5.5)$ & $5.8(5.6)$ \\
\hline \multicolumn{7}{|l|}{ Components of ACR2O and MDA } \\
\hline Number of swollen joints (0-66) & $8.6(5.8)$ & $10.9(9.3)$ & $10.1(7.1)$ & $12.9(7.8)$ & $11.7(6.8)$ & $12.3(6.9)$ \\
\hline Number of tender joints (0-68) & $17.7(13.1)$ & $20.2(14.5)$ & $19.8(14.4)$ & $22.4(13.5)$ & $19.8(11.9)$ & $21.6(13.1)$ \\
\hline CRP (mg/dL), median (IQR) & $0.6(0.3-1.3)$ & $0.7(0.4-1.9)$ & $0.8(0.3-1.5)$ & $1.2(0.6-2.3)$ & $1.3(0.7-2.5)$ & $1.2(0.5-2.6)$ \\
\hline PASI score (0-72) & $9.5(10.1)$ & $8.4(9.8)$ & $7.7(8.8)$ & $10.8(11.7)$ & $9.7(11.7)$ & $9.3(9.8)$ \\
\hline HAQ-DI (0-3) & $1.1(0.6)$ & $1.2(0.6)$ & $1.1(0.6)$ & $1.2(0.6)$ & $1.3(0.6)$ & $1.3(0.6)$ \\
\hline Patient's global assessment of arthritis (VAS 0-10) & $6.1(2.0)$ & $6.5(2.0)$ & $6.1(2.2)$ & $6.4(1.9)$ & $6.5(1.9)$ & $6.5(1.8)$ \\
\hline Patient's global assessment of pain (VAS 0-10) & $5.9(2.0)$ & $6.0(2.1)$ & $5.8(2.2)$ & $6.2(2.0)$ & $6.3(2.0)$ & $6.3(1.8)$ \\
\hline Physician's global assessment (VAS 0-10) & $6.2(1.6)$ & $6.2(1.7)$ & $6.3(1.7)$ & $6.6(1.5)$ & $6.6(1.6)$ & $6.7(1.5)$ \\
\hline Patients with enthesitis, n (\%) & $73(57 \%)$ & $72(57 \%)$ & $77(61 \%)$ & $170(69 \%)$ & $158(64 \%)$ & $178(72 \%)$ \\
\hline Leeds Enthesitis Index score (1-6) & $3.0(1.5)$ & $2.7(1.6)$ & $2.8(1.6)$ & $3.0(1.7)$ & $2.6(1.5)$ & $2.8(1.6)$ \\
\hline SF-36 PCS score (0-100) & $35.9(8.3)$ & $34.1(7.6)$ & $33.8(8.5)$ & $33.3(7.1)$ & $32.6(7.9)$ & $32.4(7.0)$ \\
\hline MCS score (0-100) & $46.5(9.8)$ & $47.0(11.1)$ & $48.7(9.6)$ & $48.4(11.0)$ & $47.4(10.8)$ & $47.2(12.0)$ \\
\hline FACIT-Fatigue score (0-52) & $31.4(10.1)$ & $29.5(11.3)$ & $30.2(9.9)$ & $30.8(9.6)$ & $29.3(9.9)$ & $29.1(9.5)$ \\
\hline
\end{tabular}

Data are mean (SD) unless otherwise indicated

$A C R 20 \geq 20 \%$ improvement in American College of Rheumatology criteria, BMI body mass index, CRP C-reactive protein, FACIT Functional Assessment of Chronic IIIness Therapy, HAQ-DI Health Assessment Questionnaire-Disability Index, IQR interquartile range, MDA minimal disease activity, PASI Psoriasis Area and Severity Index, PsA psoriatic arthritis, SD standard deviation, Q4W every 4 weeks, Q8W every 8 weeks, SF-36 PCS/MCS 36-item Short-Form physical/mental component summary, VAS visual analog scale 
and Q8W groups, respectively, compared with 2.2 in the placebo group in DISCOVER-1; respective changes in DISCOVER-2 were 7.1 and 7.6 vs 3.6 (all $P<0.001$, Fig. 2). Improvements were seen as early as week 8 in the larger DISCOVER-2 study of patients with more active disease at baseline, and by week 16 in the smaller DISCOVER-1 study that included TNFi-experienced patients. These substantial improvements in fatigue were maintained by guselkumab Q4W and Q8W through week 52, at which time LS mean changes were 6.7-6.9 and 7.2-8.4 across guselkumab arms in DISCOVER-1 and DISCOVER-2, respectively (Fig. 2).

The effect sizes of guselkumab Q4W and Q8W on changes in FACIT-Fatigue scores at week 24 were moderate in DISCOVER-1 (Cohen's $d=0.52-0.55$ ) and large in DISCOVER-2 (0.75-0.81); robust effect sizes were also seen at week 52 in the guselkumab Q4W (0.680.84 ) and Q8W (0.66-0.91) groups (Table 2).

Higher proportions of guselkumab- than placebotreated patients achieved clinically meaningful

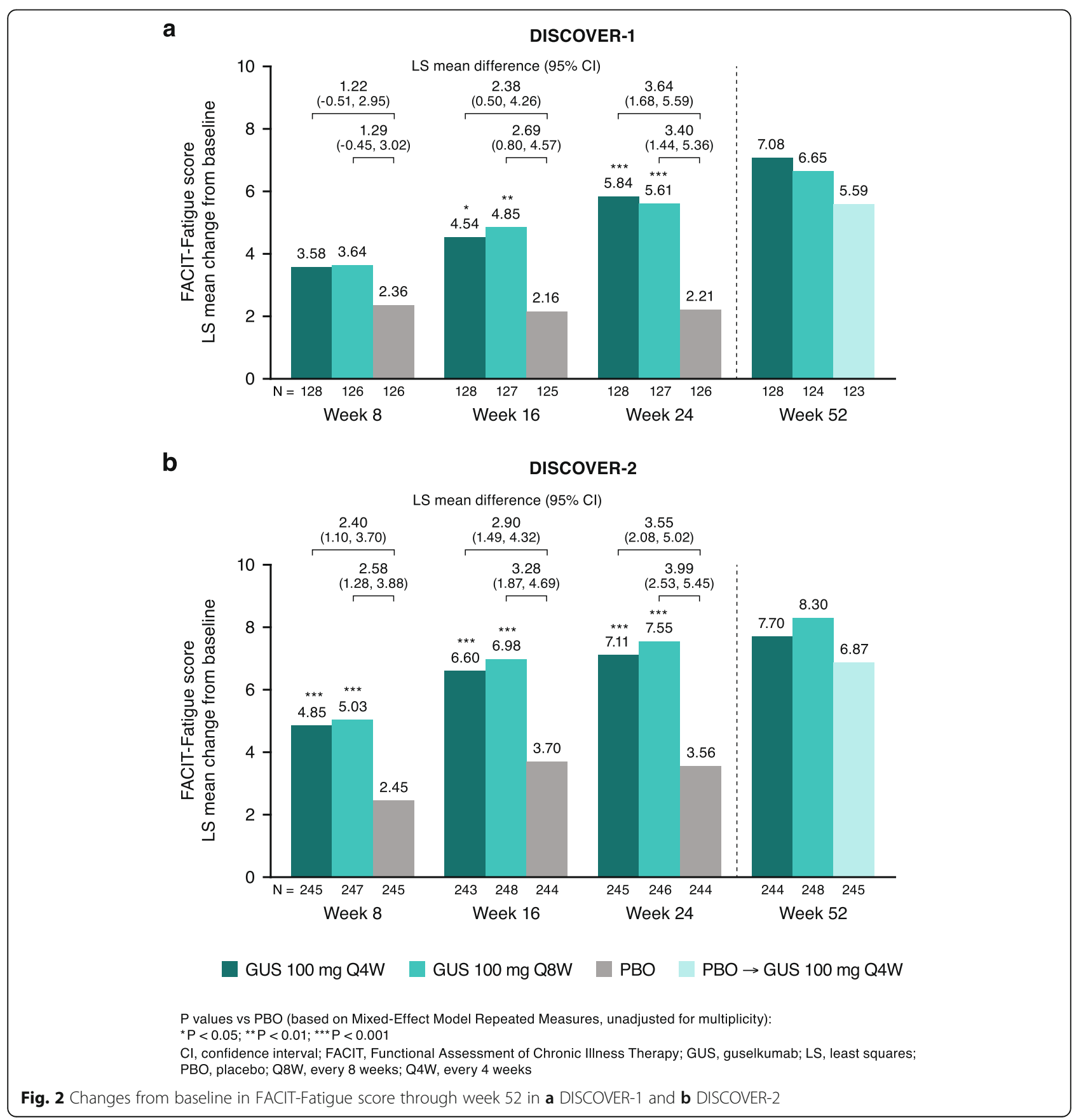


Table 2 Guselkumab treatment effect on FACIT-Fatigue score at week 24 and week 52

\begin{tabular}{|c|c|c|c|c|c|c|c|c|c|c|c|c|}
\hline & \multicolumn{6}{|c|}{ DISCOVER-1 } & \multicolumn{6}{|c|}{ DISCOVER-2 } \\
\hline & \multicolumn{2}{|c|}{$\begin{array}{l}\text { Guselkumab } \\
100 \text { mg Q4W }\end{array}$} & \multicolumn{2}{|c|}{$\begin{array}{l}\text { Guselkumab } \\
100 \text { mg Q8W }\end{array}$} & \multicolumn{2}{|c|}{$\begin{array}{l}\text { Placebo to } \\
\text { Guselkumab } \\
100 \mathrm{mg} \text { Q4W } \\
\text { at W24 }\end{array}$} & \multicolumn{2}{|c|}{$\begin{array}{l}\text { Guselkumab } \\
100 \text { mg Q4W }\end{array}$} & \multicolumn{2}{|c|}{$\begin{array}{l}\text { Guselkumab } \\
100 \mathrm{mg} \text { Q8W }\end{array}$} & \multicolumn{2}{|c|}{$\begin{array}{l}\text { Placebo to } \\
\text { Guselkumab } \\
100 \text { mg Q4W } \\
\text { at W24 }\end{array}$} \\
\hline & W 24 & W 52 & W 24 & W 52 & W 24 & W 52 & W 24 & W 52 & W 24 & W 52 & W 24 & W 52 \\
\hline N & 125 & 124 & 123 & 114 & 114 & 104 & 234 & 229 & 238 & 234 & 237 & 230 \\
\hline Observed mean change in FACIT-Fatigue score & 5.6 & 6.9 & 5.9 & 7.5 & 2.6 & 6.6 & 7.0 & 7.7 & 8.0 & 8.9 & 3.8 & 7.5 \\
\hline$(\mathrm{SD})$ & $(7.8)$ & $(8.4)$ & $(10.4)$ & (9.6) & $(8.3)$ & $(9.4)$ & $(8.6)$ & $(9.1)$ & $(9.9)$ & $(9.5)$ & $(9.0)$ & (9.4) \\
\hline Cohen's $d$ effect size ${ }^{a}$ & 0.55 & 0.68 & 0.52 & 0.66 & 0.26 & 0.65 & 0.75 & 0.84 & 0.81 & 0.91 & 0.41 & 0.80 \\
\hline
\end{tabular}

FACIT Functional Assessment of Chronic Illness Therapy, Q4W every 4 weeks, Q8W every 8 weeks, SD standard deviation, $W$ week

${ }^{a}$ The effect size of changes from baseline in FACIT-Fatigue scores, based on the observed data, was calculated by dividing the change in FACIT-Fatigue score from baseline by the SD of baseline scores [24]

improvements ( $\geq 4$-point increase) in FACIT-Fatigue scores, beginning at week 8 (DISCOVER-2) or week 16 (DISCOVER-1). At week 24, significantly greater proportions of guselkumab-randomized patients achieved such improvements in FACIT-Fatigue scores when compared with placebo, i.e., and 63\% (Q4W, $\mathrm{P}<0.001)$ and $54 \%$ (Q8W, $\mathrm{P}<0.01$ ) vs $35 \%$ in DISCOVER-1 and 60\% (Q4W, $\mathrm{P}<0.01)$ and $61 \% \quad(\mathrm{Q} 8 \mathrm{~W}, \quad \mathrm{P}<0.001) \quad$ vs $46 \%$ in DISCOVER-2. At week 52, 55-62\% of patients randomized to guselkumab in DISCOVER-1 and $64-66 \%$ in DISCOVER-2 demonstrated a clinically meaningful improvement in fatigue (Fig. 3).

Patients who switched from placebo to guselkumab $100 \mathrm{mg}$ Q4W at week 24 demonstrated changes from baseline and achievement of clinically meaningful improvements in FACIT-Fatigue score at week 52 comparable to those seen in patients originally randomized to guselkumab (Figs. 2 and 3).

\section{Cumulative distribution of improvements in FACIT- Fatigue scores at week 24}

As shown in Fig. 4, clear separation between both guselkumab dosing regimens and placebo was observed over a range of changes from baseline in FACIT-Fatigue scores. More specifically, numerically larger proportions of patients in both the guselkumab Q4W and Q8W vs placebo groups achieved $\geq 2$ to $\geq 12$-point increases from baseline in FACIT-Fatigue scores at week 24 .

\section{Mediation analyses}

Results of mediation analyses indicated that improvements in the FACIT-Fatigue score observed among guselkumab-treated patients at week 24 were partially mediated indirectly through achievement of ACR20 response. With guselkumab Q4W, 69\% and 70\% of guselkumab's impact on FACIT-Fatigue scores was independent of effects mediated through ACR20. For guselkumab Q8W, 12\% and 36\% of the effect on FACITFatigue scores in DISCOVER-1 and DISCOVER-2, respectively, was independent of those mediated by achievement of ACR20 response. Independent treatment effects of guselkumab on FACIT-Fatigue scores were also observed after adjusting for other clinical outcomes, including achievement of MDA target and change from baseline in CRP concentration at week 24 (Table 3). The relative magnitudes of the direct vs indirect (mediated) effect of guselkumab on fatigue and the extent of differences between dosing regimens varied among the clinical endpoints examined.

\section{Discussion}

Guselkumab provided clinically meaningful improvements in fatigue among patients with active PsA who participated in the pivotal, phase 3, DISCOVER-1 and DISCOVER-2 trials. Guselkumab treatment effects on changes from baseline in FACIT-Fatigue scores were observed as early as week 8 in DISCOVER-2 patients, who were biologic-naïve and demonstrated more active disease at baseline, and by week 16 in DISCOVER-1 patients, one-third of whom were TNFi-experienced. The greater average improvements, and proportions of patients experiencing clinically meaningful improvement ( $\geq 4$ points), in fatigue seen at week 24 were maintained in the groups of patients who continued to receive guselkumab through week 52. Guselkumab was estimated to have a moderate- (DISCOVER-1) to-large (DISCOVER-2) effect on improving FACIT-Fatigue scores through 1 year. Additionally, mediation analyses demonstrated that substantial proportions of the effects of guselkumab Q4W and Q8W vs placebo on fatigue were direct effects, after adjusting for achievement of ACR20 and MDA responses or change in serum CRP concentrations.

Fatigue is common in PsA, and moderate-to-severe fatigue has been reported by $30-50 \%$ of patients with PsA [5-9]. Although this important symptom can be neglected by physicians when assessing disease severity in rheumatological disorders [29, 30], PsA patients 


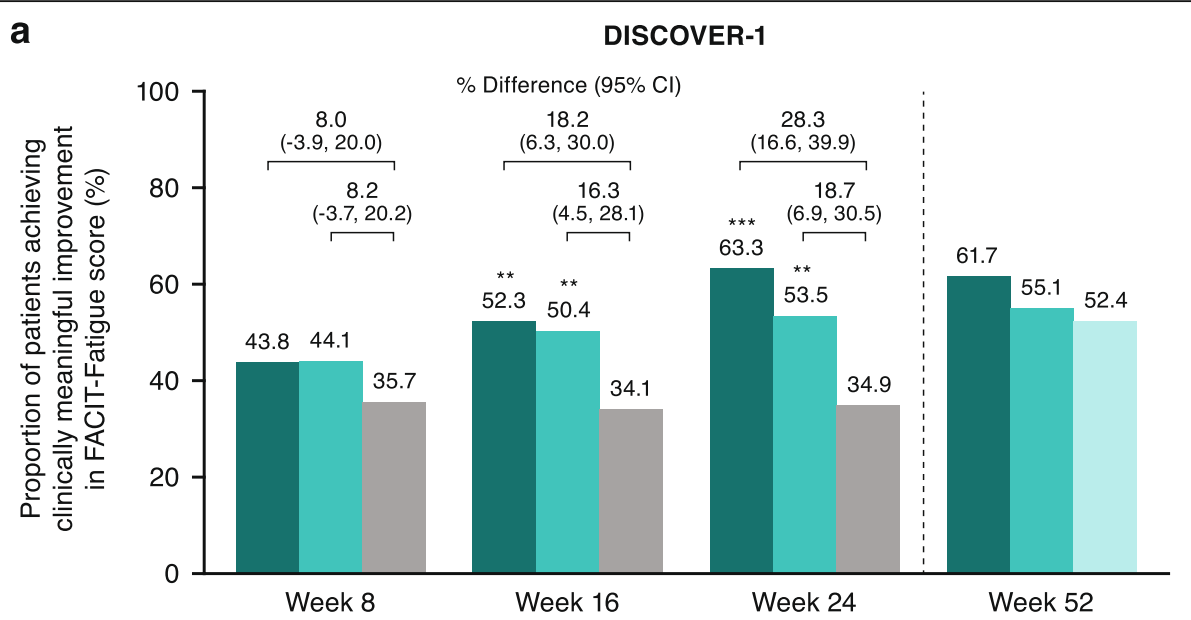

GUS $100 \mathrm{mg}$ Q4W ( $N=128)$, GUS $100 \mathrm{mg}$ Q8W $(\mathrm{N}=127), \mathrm{PBO}(\mathrm{N}=126), \mathrm{PBO} \rightarrow$ GUS $100 \mathrm{mg}$ Q4W $(\mathrm{N}=126)$

b

DISCOVER-2

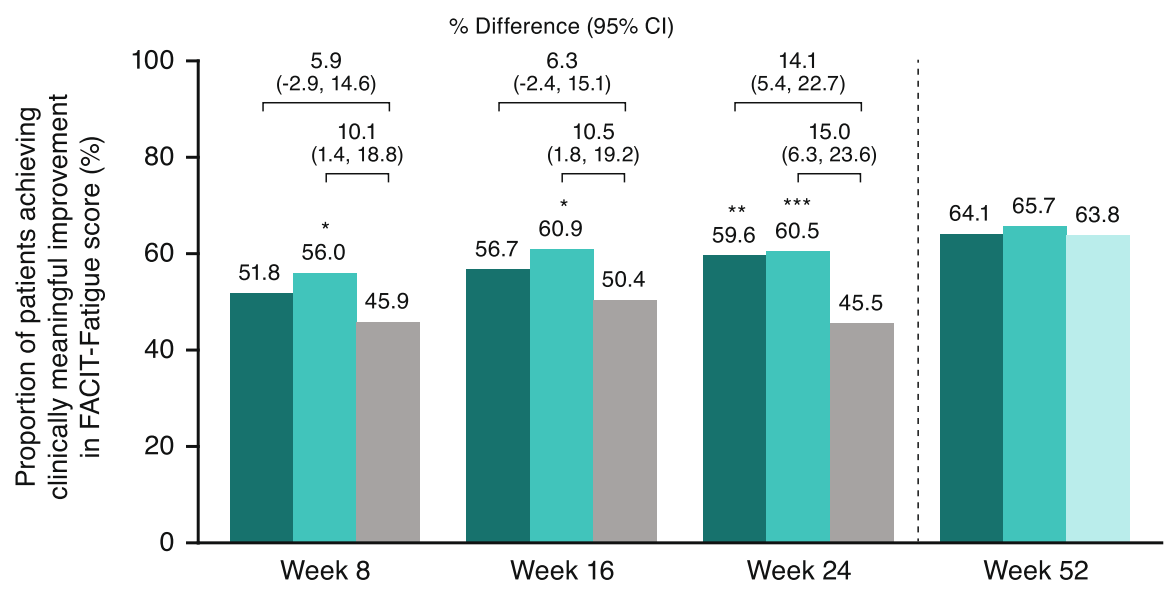

GUS $100 \mathrm{mg}$ Q4W ( $N=245)$, GUS $100 \mathrm{mg}$ Q8W ( $\mathrm{N}=248), \mathrm{PBO}(\mathrm{N}=246)$, PBO $\rightarrow$ GUS $100 \mathrm{mg}$ Q4W $(\mathrm{N}=246)$

GUS 100 mg Q4W GUS 100 mg Q8W PBO PBO $\rightarrow$ GUS 100 mg Q4W

$P$ values vs $\mathrm{PBO}$ (based on Cochran-Mantel-Haenszel test, unadjusted for multiplicity):

${ }^{\star} \mathrm{P}<0.05 ;{ }^{\star \star} \mathrm{P}<0.01 ;{ }^{\star \star \star} \mathrm{P}<0.001$

$\mathrm{Cl}$, confidence interval; FACIT, Functional Assessment of Chronic Illness Therapy; GUS, guselkumab; PBO, placebo; Q8W, every 8 weeks; Q4W, every 4 weeks

Fig. 3 Proportion of patients achieving clinically meaningful improvement in FACIT-Fatigue score ( $\geq 4$-point increase [21]) through week 52 in a DISCOVER-1 and $\mathbf{b}$ DISCOVER-2

consider fatigue as the second or third most important health domain impacting their life and as a top priority for improvement $[5,6,29]$. Higher levels of fatigue in patients with PsA have been associated with greater work impairment, more work time missed, greater impairment while performing daily activities, higher pain scores, and diminished persistence of TNFi treatment $[15,31]$. Recently, a multinational real-world PsA study demonstrated that, despite TNFi treatment, substantial fatigue persisted and was significantly associated with reduced work productivity [32]. Such findings highlight the importance of managing fatigue in PsA patients, as well as the need to assess fatigue accurately and identify effective treatment options [13].

Utilizing data derived from the 1120 PsA patients evaluated in DISCOVER-1 and DISCOVER-2, we assessed patients' fatigue via the FACIT-Fatigue scale, an instrument that has been validated in patients with PsA [20, 21]. At baseline, patients in both DISCOVER trials had mean (SD) FACIT-Fatigue scores ranging from 29.1 (9.5) to 31.4 (10.1), compared with 43.6 (9.4), based on limited studies in a US population, and 23.9 (12.6) in patients with cancer-related anemia [23]. These data highlight the substantial levels of fatigue experienced by these PsA patients. 


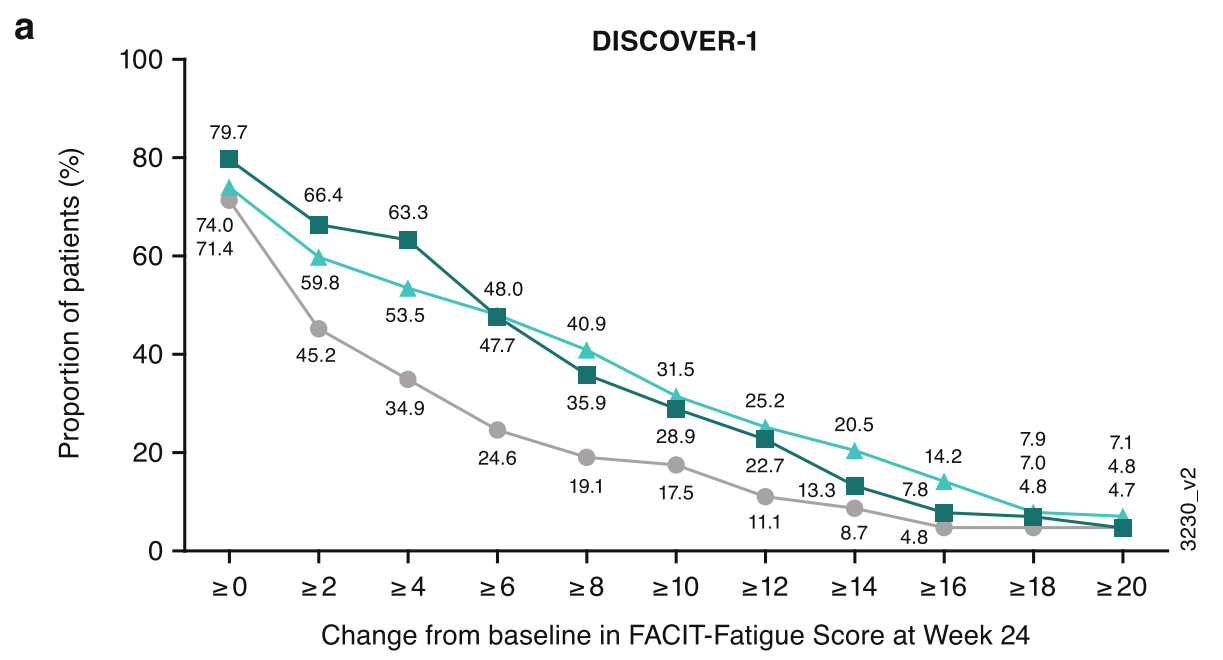

GUS $100 \mathrm{mg}$ Q4W ( $\mathrm{N}=128)$, GUS $100 \mathrm{mg}$ Q8W ( $=127)$, PBO $(\mathrm{N}=126)$

b

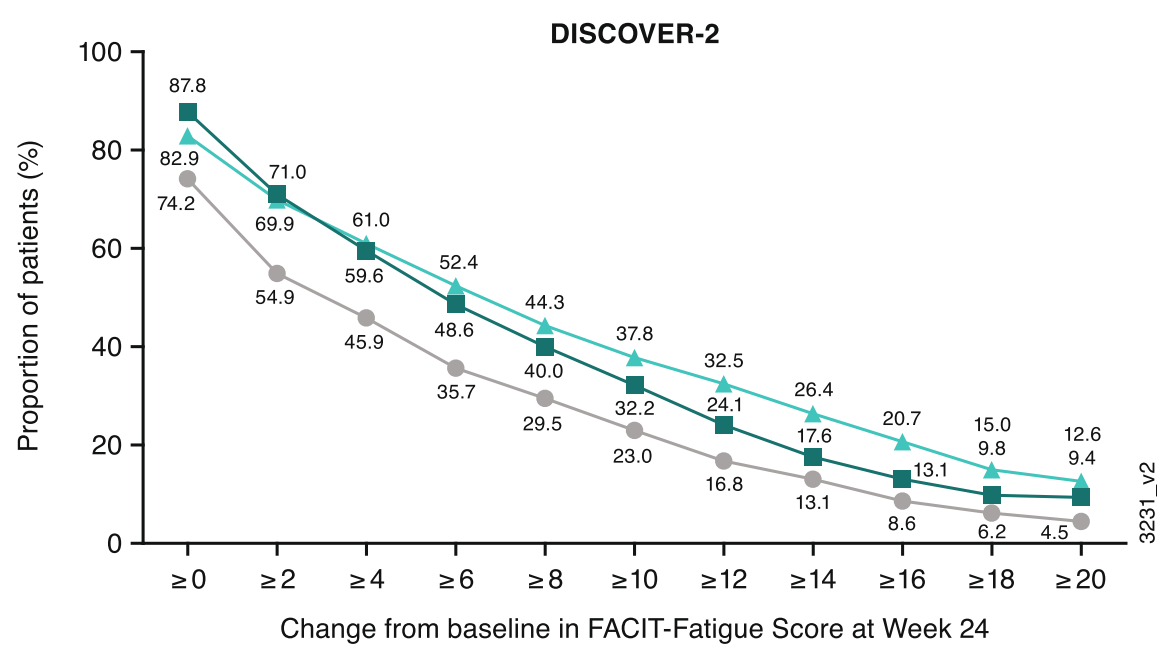

GUS $100 \mathrm{mg}$ Q4W $(\mathrm{N}=245)$, GUS $100 \mathrm{mg}$ Q8W $(\mathrm{N}=246)$, PBO $(\mathrm{N}=244)$

$\dashv$ GUS $100 \mathrm{mg} \mathrm{Q4W}-$ GUS $100 \mathrm{mg} \mathrm{Q8W}-$ PBO

FACIT, Functional Assessment of Chronic Illness Therapy; GUS, guselkumab; PBO, placebo; $\mathrm{Q} 8 \mathrm{~W}$, every 8 weeks; Q4W, every 4 weeks

Fig. 4 Modified cumulative distribution curves of changes in FACIT-Fatigue score at week 24 in a DISCOVER-1 and b DISCOVER-2

Numerous scales have been used to measure fatigue [20, 33-37]. The FACIT-Fatigue scale [20] and the Fatigue Numeric Rating Scale [37] have the advantage of being validated for PsA. Several controlled studies of biologics for PsA have evaluated fatigue using these validated scales, as well as more general scales [12, 38-43]. However, the description of results on fatigue from these studies is typically limited in the published literature. In a recent analysis of 880 patients with PsA and fatigue in the DANBIO registry, less than half of the patients achieved 50\% improvement in their Fatigue VAS after 6 months of treatment with their initial TNFi [15].
Similarly, in a meta-analysis of patients with active rheumatoid arthritis, treatment with biologics was found to lead to only small-to-moderate improvements in fatigue [44]. Here, in addition to employing a fatigue scale validated for PsA $[20,21]$, and a cut-point in that scale that has been shown to define minimal clinically meaningful improvement [21], we employed modified cumulative distribution plots to demonstrate achievement of varying levels of improvement in FACIT-Fatigue scores. Importantly, in addition to a greater proportion of patients in the guselkumab vs placebo groups achieving the $\geq 4$-point threshold of 
Table 3 Mediation analysis of the effects of clinical responses on changes in FACIT-Fatigue scores through week 24

\begin{tabular}{|c|c|c|c|c|}
\hline Clinical response & & Effect & $\begin{array}{l}\text { Guselkumab } 100 \mathrm{mg} \text { Q4W vs placebo } \\
\text { Estimate }(95 \% \mathrm{Cl})\end{array}$ & $\begin{array}{l}\text { Guselkumab } 100 \mathrm{mg} \text { Q8W vs placebo } \\
\text { Estimate }(95 \% \mathrm{Cl})\end{array}$ \\
\hline \multirow[t]{10}{*}{ ACR20 } & DISCOVER-1 & NDE & $2.60(0.58,4.46)^{*}$ & $0.36(-1.72,2.40)$ \\
\hline & & NIE & $1.20(0.27,2.31)^{*}$ & $2.75(1.38,4.32)^{*}$ \\
\hline & & Total effect & $3.79(1.94,5.44)^{*}$ & $3.12(1.05,5.15)^{*}$ \\
\hline & & $\%$ Indirect (mediated) effect & $31.5 \%$ & $88.3 \%$ \\
\hline & & $\%$ Direct effect & $68.5 \%$ & $11.7 \%$ \\
\hline & DISCOVER-2 & NDE & $2.49(0.96,4.14)^{*}$ & $1.44(-0.11,2.97)$ \\
\hline & & NIE & $1.09(0.42,1.95)^{*}$ & $2.53(1.62,3.64)^{*}$ \\
\hline & & Total effect & $3.58(2.10,5.05)^{*}$ & $3.97(2.41,5.53)^{*}$ \\
\hline & & $\%$ Indirect (mediated) effect & $30.3 \%$ & $63.7 \%$ \\
\hline & & $\%$ Direct effect & $69.7 \%$ & $36.3 \%$ \\
\hline \multirow[t]{10}{*}{ MDA } & DISCOVER-1 & NDE & $2.84(0.97,4.71)^{*}$ & $2.34(0.24,4.45)^{*}$ \\
\hline & & NIE & $0.78(0.16,1.40)^{*}$ & $0.74(0.09,1.39)^{*}$ \\
\hline & & Total effect & $3.62(1.76,5.49)^{*}$ & $3.08(0.99,5.18)^{*}$ \\
\hline & & $\%$ Indirect (mediated) effect & $21.6 \%$ & $24.0 \%$ \\
\hline & & $\%$ Direct effect & $78.4 \%$ & $76.0 \%$ \\
\hline & DISCOVER-2 & NDE & $3.13(1.63,4.63)^{*}$ & $2.67(1.09,4.26)^{*}$ \\
\hline & & NIE & $0.28(0.07,0.50)^{*}$ & $1.06(0.49,1.64)^{*}$ \\
\hline & & Total effect & $3.41(1.96,4.86)^{*}$ & $3.74(2.13,5.34)^{*}$ \\
\hline & & $\%$ Indirect (mediated) effect & $8.3 \%$ & $28.5 \%$ \\
\hline & & $\%$ Direct effect & $91.7 \%$ & $71.5 \%$ \\
\hline \multirow[t]{10}{*}{ Change in CRP } & DISCOVER-1 & NDE & $3.19(1.37,5.02)^{*}$ & $2.51(0.52,4.50)^{*}$ \\
\hline & & NIE & $0.42(-0.03,0.86)$ & $0.56(-0.10,1.22)$ \\
\hline & & Total effect & $3.61(1.74,5.47)^{*}$ & $3.06(0.95,5.17)^{*}$ \\
\hline & & $\%$ Indirect (mediated) effect & $11.6 \%$ & $18.2 \%$ \\
\hline & & $\%$ Direct effect & $88.4 \%$ & $81.8 \%$ \\
\hline & DISCOVER-2 & NDE & $2.88(1.36,4.41)^{*}$ & $3.20(1.62,4.79)^{*}$ \\
\hline & & NIE & $0.49(-0.07,1.05)$ & $0.60(0.05,1.14)^{*}$ \\
\hline & & Total effect & $3.37(1.93,4.81)^{*}$ & $3.80(2.24,5.36)^{*}$ \\
\hline & & $\%$ Indirect (mediated) effect & $14.5 \%$ & $15.7 \%$ \\
\hline & & \% Direct effect & $85.5 \%$ & $84.3 \%$ \\
\hline
\end{tabular}

ACR20 and MDA were dichotomous mediators; change in CRP was a continuous mediator

$A C R 20 \geq 20 \%$ improvement in American College of Rheumatology criteria, CRP C-reactive protein, FACIT Functional Assessment of Chronic Illness Therapy, MDA minimal disease activity, NDE natural direct effect (effect on FACIT-F beyond the effect on the clinical response), NIE natural indirect effect (effect on FACIT-F mediated by clinical response), Q4W every 4 weeks, Q8W every 8 weeks

*P vs placebo $<0.05$

clinically meaningful improvement in FACIT-Fatigue score [21] at week 24, cumulative distribution curves also demonstrated a clear separation of both guselkumab groups from placebo over a broad range of cutpoints of improvement $(\geq 2$ to $\geq 12$ ) during this timeframe. In addition, by conducting analyses separately for the similarly designed DISCOVER-1 and DISCOVER-2 studies, we were able to evaluate the consistency of guselkumab's effect on fatigue across a broad population of patients with differing degrees of active PsA at the study outset. Unfortunately, cross-study comparisons with other biologics are constrained by differences in study designs, patient populations, and scales used to measure fatigue.

Mediation analysis is a statistical technique employed to explore mechanisms underlying an observed relationship between an exposure variable and an outcome variable and how they relate to a third intermediate variable, the mediator [26, 27]. To investigate the mechanism by which guselkumab improves fatigue in PsA, we employed this computational model to distinguish direct effects of guselkumab treatment on fatigue from indirect 
effects, i.e., those influenced by improvement in an intermediate factor such as signs and symptoms of arthritis and/or systemic inflammation. Achievement of an ACR20 response was the prespecified mediator in these analyses, and post hoc analyses utilized achievement of MDA or changes in serum CRP levels as alternative mediators of guselkumab's effect on FACIT-Fatigue scores. Results of the prespecified analysis indicated approximately one-third and two-thirds of the improvement in fatigue with guselkumab Q8W and Q4W, respectively, at week 24 was independent of the drug's effect on achievement of ACR20 response and therefore not simply mediated by improvement in this particular constellation of PsA signs and symptoms. Results of the post hoc analyses assessing achievement of MDA or changes in serum CRP levels as mediators also indicated that guselkumab exerted an effect on fatigue independent from achievement of MDA response and altered systemic inflammation. Relative to mean change data, results across the conducted mediation analyses indicated the direct treatment effect of guselkumab on FACITFatigue score was numerically greater with Q4W than Q8W dosing. These differences, which are inconsistent across outcome variables tested, could derive from small numerical differences in baseline disease characteristics across treatment groups and/or data variability across the various ACR and MDA components. Although findings are applied to both guselkumab dosing regimens, across the three potential mediators assessed, results are based on a statistical technique and should be interpreted with caution. Additional analyses are warranted to explore any true differences between the two guselkumab dosing regimens.

Fatigue is highly subjective, and the source is complex, undefined, and likely multidimensional [4]. Despite this, to develop more effective treatments, it is important to understand the mechanism of fatigue in PsA. Fatigue is a frequent symptom in inflammatory rheumatic diseases $[2,3]$ and has been postulated to be mediated in part by Th1 and Th17 pro-inflammatory cytokines in multiple sclerosis, another inflammatory autoimmune disorder [45]. Given that the IL-23/Th17 pathway is crucial to PsA pathogenesis and targeted biologic therapy [46] and that guselkumab specifically targets IL-23 through its p19 subunit, the direct effects of guselkumab on FACITFatigue scores in patients with PsA could derive from its action on yet-to-be identified fatigue-specific inflammatory pathways, either alone or in combination with other factors. Further exploration is clearly needed.

Improvements in FACIT-Fatigue score in patients with PsA have also been observed with other biologics targeting different pathways [12, 39]. However, due to inherent differences in study populations, designs, and assessment tools, direct comparisons between treatments cannot be made without a head-to-head comparitive trial. As such, results of the current analysis are specific to the effects of guselkumab and cannot be compared with or extrapolated to effects of other biologic therapies. Additional research utilizing data from activecomparator studies may help to differentiate biologics in their ability to treat fatigue; such information would be useful to both physicians and patients in selecting treatments. As mentioned above, we employed computational methods in an effort to distinguish direct from indirect effects of guselkumab on fatigue. Results of these mediation analyses indicate guselkumab's effect on fatigue is not solely dependent on its effects on achievement of ACR or MDA response, or CRP. However, these findings should be interpreted with caution given the multifactorial causation of fatigue. Future research will need to evaluate the effect of guselkumab on additional potential drivers of fatigue, e.g., activity, sleep, mental health, and anemia. Also, given the contribution of fatigue to disease burden in patients with psoriasis [47], future analyses should investigate direct treatment effects on fatigue in cohorts of patients with psoriasis. Finally, despite employing a conservative estimate of minimal clinically meaningful improvement in FACITFatigue sores, we observed a relatively high placebo response rate, particularly in DISCOVER-2. However, the cumulative distribution curves confirmed that both guselkumab dosing regimens demonstrated clear separation from placebo across a range of change cut-points (i.e., $\geq 2$ to $\geq 12$ ).

\section{Conclusions}

Taken together, results of these analyses indicate a strong impact of guselkumab on the fatigue of PsA when assessed via the FACIT-Fatigue instrument. Although further research is needed to more fully characterize the mechanism by which guselkumab improves patient fatigue, our findings may further inform treatment decisions [16], additional research on this topic, and future consensus deliberations surrounding PsA core set assessments.

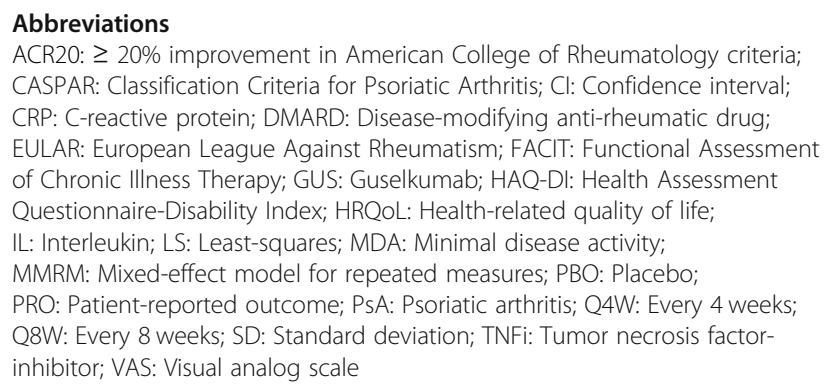

Acknowledgements

The authors thank Michelle Perate, MS, of Janssen Scientific Affairs, LLC for the substantive manuscript review, and Cynthia Guzzo, MD, and Elizabeth 
Rosenberg, PhD, both employed by Kelly Services, for writing support funded by Janssen.

\section{Authors' contributions}

$\mathrm{APK}, \mathrm{ECH}, \mathrm{BZ}, \mathrm{XL}, \mathrm{MS}, \mathrm{CSK}$, and $\mathrm{CH}$ contributed to the study design and data collection, analysis, and interpretation. PR, PJM, PSH, AD, LG, and AK contributed to the data collection and/or data interpretation. All authors revised the manuscript and gave final approval for submission.

\section{Funding}

This study was funded by Janssen Research \& Development, LLC

\section{Availability of data and materials}

The data sharing policy of Janssen Pharmaceutical Companies of Johnson \& Johnson is available at https://www.janssen.com/clinical-trials/transparency. As noted on this site, requests for access to the study data can be submitted through Yale Open Data Access (YODA) Project site at http://yoda.yale.edu.

\section{Declarations}

\section{Ethics approval and consent to participate}

The DISCOVER-1 and DISCOVER-2 trials were conducted in accordance with Good Clinical Practice and the Declaration of Helsinki. The protocols were approved by Institutional Review Boards. All patients gave written informed consent before any study-related procedures were performed.

\section{Consent for publication}

Not applicable.

\section{Competing interests}

PR has received research support (Janssen, Novartis), consulting fees (AbbVie, Amgen, Bristol Myers Squibb, Celgene, Eli Lilly, Janssen, Novartis, Pfizer, Roche, and UCB), and speakers bureau support (AbbVie, Janssen, Eli Lilly, Novartis, Pfizer, and UCB). PJM has received research support, consulting fees (AbbVie, Amgen, Bristol Myers Squibb, Galapagos, Gilead, Janssen, Eli Lilly, Novartis, Pfizer, SUN, and UCB) and consulting fees (Boehringer Ingelheim and GlaxoSmithKline). PSH has received research support and non-financial support (AbbVie), research support (Janssen, Pfizer), and consulting fees (Janssen, Galapagos, and Novartis). AD has received research support (AbbVie, Eli Lilly, GlaxoSmithKline, Novartis, Pfizer, and UCB), consulting fees (AbbVie, Amgen, Boehringer Ingelheim, Bristol Myers Squibb, Celgene, Eli Lilly, Galapagos, GlaxoSmithKline, Janssen, Novartis, Pfizer, and UCB), and speakers bureau support (AbbVie, Eli Lilly, Janssen, Novartis, Pfizer, and UCB). LG has received research grants (Amgen, Galapagos, Janssen, Eli Lilly, Pfizer, Sandoz, and Sanofi) and consulting fees (AbbVie, Amgen, Bristol Myers Squibb, Biogen, Celgene, Gilead, Janssen, Eli Lilly, Novartis, Pfizer, Samsung Bioepis, Sanofi-Aventis, and UCB). AK has received research support and/or consulting fees (AbbVie, Amgen, Bristol Myers Squibb, Genentech, Janssen, Eli Lilly, Merck, Novartis, Pfizer, and UCB). APK, ECH, BZ, XL, MS, CSK, and CH are employed by subsidiaries of, and own stock in, Johnson \& Johnson.

\section{Author details Leeds, UK. ${ }^{4}$ Oregon Health \& Science University, Portland, OR, USA. Publique, Paris, France. ${ }^{6} \mathrm{AP}-\mathrm{HP}$ Pitié-Salpêtrière Hospital, Paris, France. USA. \\ Received: 8 February 2021 Accepted: 10 June 2021 \\ Published online: 14 July 2021}

${ }^{1}$ Memorial University of Newfoundland, St. Johns, Newfoundland, Canada. ${ }^{2}$ Swedish Medical Center/Providence St. Joseph Health and University of Washington School of Medicine, Seattle, WA, USA. ${ }^{3}$ University of Leeds, ${ }^{5}$ Sorbonne Université, Institut Pierre Louis d'Epidémiologie et de Santé ${ }^{7}$ University of California San Diego, La Jolla, CA, USA. ${ }^{8}$ Janssen Research \& Development, LLC, San Diego, CA, USA. ${ }^{9}$ Janssen Research \& Development, LLC, Spring House, PA 19436, USA. ${ }^{10}$ Univerisity of Pennsylvania School of Medicine, Philadelphia, PA, USA. " 'Janssen Global Services, LLC, Horsham, PA,

\section{References}

1. Ritchlin CT, Colbert RA, Gladman DD. Psoriatic arthritis. N Engl J Med. 2017; 376(10):957-70 https://doi.org/10.1056/NEJMra1505557.
2. Norheim KB, Jonsson G, Omdal R. Biological mechanisms of chronic fatigue. Rheumatology (Oxford). 2011;50(6):1009-18 https://doi.org/10.1093/rheuma tology/keq454.

3. Louati K, Berenbaum F. Fatigue in chronic inflammation - a link to pain pathways. Arthritis Res Ther. 2015;17(1):254.

4. Krajewska-Wlodarczyk M, Owczarczyk-Saczonek A, Placek W. Fatigue - an underestimated symptom in psoriatic arthritis. Reumatologia. 2017;55(3): 125-30 https://doi.org/10.5114/reum.2017.68911.

5. Gossec L, de Wit M, Kiltz U, Braun J, Kalyoncu U, Scrivo R, et al. A patientderived and patient-reported outcome measure for assessing psoriatic arthritis: elaboration and preliminary validation of the Psoriatic Arthritis Impact of Disease (PSAID) questionnaire, a 13-country EULAR initiative. Ann Rheum Dis. 2014;73(6):1012-9 https://doi.org/10.1136/annrheumdis-2014-2 05207.

6. Gudu T, Etcheto A, de Wit M, Heiberg T, Maccarone M, Balanescu A, et al. Fatigue in psoriatic arthritis - a cross-sectional study of 246 patients from 13 countries. Joint Bone Spine. 2016;83(4):439-43 https://doi.org/10.1016/j. jbspin.2015.07.017.

7. Husted JA, Tom BDM, Schentag CT, Farewell VT, Gladman DD. Occurrence and correlates of fatigue in psoriatic arthritis. Ann Rheum Dis. 2009;68(10): 1553-8 https://doi.org/10.1136/ard.2008.098202.

8. Husted JA, Tom BD, Farewell VT, Gladman DD. Longitudinal analysis of fatigue in psoriatic arthritis. J Rheumatol. 2010;37(9):1878-84 https://doi. org/10.3899/jrheum.100179.

9. Tobin AM, Sadlier M, Collins P, Rogers S, FitzGerald O, Kirby B. Fatigue as a symptom in psoriasis and psoriatic arthritis: an observational study. $\mathrm{Br} J$ Dermatol. 2017;176(3):827-8 https://doi.org/10.1111/bjd.15258.

10. Gossec L, Baraliakos X, Kerschbaumer A, de Wit M, Mclnnes I, Dougados M, et al. EULAR recommendations for the management of psoriatic arthritis with pharmacological therapies: 2019 update. Ann Rheum Dis. 2020;79(6): 700-12 https://doi.org/10.1136/annrheumdis-2020-217159.

11. Orbai M, de Wit M, Mease PJ, Callis Duffin K, Elmamoun M, Tillett W, et al. Updating the psoriatic arthritis (PSA) core domain set: a report from the PSA workshop at OMERACT 2016. J Rheumatol. 2017;44(10):1522-8 https://doi. org/10.3899/jrheum.160904.

12. Strand V, Mease P, Gossec L, Elkayam O, van den Bosch F, Zuazo J, et al. Secukinumab improves patient-reported outcomes in subjects with active psoriatic arthritis: results from a randomised phase III trial (FUTURE 1). Ann Rheum Dis. 2017;76(1):203-7 https://doi.org/10.1136/annrheumdis-2015-2 09055.

13. Reygaerts T, Mitrovic S, Fautrel B, Gossec L. Effect of biologics on fatigue in psoriatic arthritis: a systematic literature review with meta-analysis. Joint Bone Spine. 2018;85(4):405-10 https://doi.org/10.1016/j.jbspin.2018.01.011.

14. Orbai AM, Gladman DD, Goto H, Birt JA, Gellett AM, Lin CY, et al. Rapid and sustained improvements in patient-reported signs and symptoms with ixekizumab in biologic-naive and TNF-inadequate responder patients with psoriatic arthritis. Clin Exp Rheumatol. 2021;39(2):329-36.

15. Jorgensen TS, Skougaard M, Hansen RL, Ballegaard C, Mease P, Strand V, et al. Relation between fatigue and ACR response in patients with psoriatic arthritis treated with TNFi therapy: a population-based cohort study. J Rheumatol. 2020:48(6):829-35 https://doi.org/10.3899/jrheum.191107.

16. TREMFYA ${ }^{(R)}$ [package insert]. Horsham: Janssen Biotech, Inc;; 2020.

17. Deodhar A, Helliwell PS, Boehncke WH, Kollmeier AP, Hsia EC, Subramanian RA et al. Guselkumab in patients with active psoriatic arthritis who were biologicnaive or had previously received TNFa inhibitor treatment (DISCOVER-1): a double-blind, randomised, placebo-controlled phase 3 trial. Lancet. 2020; 395(10230):1115-25 https://doi.org/10.1016/S0140-6736(20)30265-8.

18. Mease PJ, Rahman P, Gottlieb AB, Kollmeier AP, Hsia EC, Xu XL, et al. Guselkumab in biologic-naive patients with active psoriatic arthritis (DISCOVER-2): a double-blind, randomised, placebo-controlled phase 3 trial. Lancet. 2020;395(10230):1126-36 https://doi.org/10.1016/S0140-6736(20)302 63-4.

19. McInnes IB, Rahman P, Gottlieb AB, Hsia EC, Kollmeier AP, Chakravarty SD, et al. Efficacy and safety of guselkumab, an interleukin-23p19-specific monoclonal antibody, through 1 year in biologic-naiive psoriatic arthritis patients. Arthritis Rheumatol. 2021;73(4):604-16 https://doi.org/10.1002/a rt.41553.

20. Chandran V, Bhella S, Schentag C, Gladman DD. Functional assessment of chronic illness therapy-fatigue scale is valid in patients with psoriatic arthritis. Ann Rheum Dis. 2007;66(7):936-9 https://doi.org/10.1136/ard.2006. 065763. 
21. Cella D, Wilson H, Shalhoub H, Revicki DA, Cappelleri JC, Bushmakin AG, et al. Content validity and psychometric evaluation of Functional Assessment of Chronic Illness Therapy-Fatigue in patients with psoriatic arthritis. J Patient Rep Outcomes. 2019;3(1):30 https://doi.org/10.1186/s41 687-019-0115-4

22. Taylor W, Gladman D, Helliwell P, Marchesoni A, Mease P, Mielants H. Classification criteria for psoriatic arthritis: development of new criteria from a large international study. Arthritis Rheum. 2006;54(8):2665-73 https://doi. org/10.1002/art.21972.

23. Cella D, Lai JS, Chang CH, Peterman A, Slavin M. Fatigue in cancer patients compared with fatigue in the general United States population. Cancer. 2002;94(2):528-38 https://doi.org/10.1002/cncr.10245.

24. Cohen J. Statistical power analysis for the behavioral sciences. New York: Academic Press; 1988.

25. US Food and Drug Administration. Guidance for Industry. Patient-reported outcome measures: use in medical product development to support labeling claims. 2009. http://www.fda.gov/downloads/Drugs/Guida nceComplianceRegulatoryInformation/Guidances/UCM193282.pdf.

26. Mackinnon DP. Introduction to statistical mediation analysis. New York: Routledge; 2008.

27. Valeri L, VanderWeele TJ. Mediation analysis allowing for exposure-mediator interactions and causal interpretation: theoretical assumptions and implementation with SAS and SPSS macros. Psychol Methods. 2013;18(2): 137-50 https://doi.org/10.1037/a0031034.

28. Coates LC, Fransen J, Helliwell PS. Defining minimal disease activity in psoriatic arthritis: a proposed objective target for treatment. Ann Rheum Dis. 2010;69(1):48-53 https://doi.org/10.1136/ard.2008.102053.

29. Eder L, Thavaneswaran A, Chandran V, Cook R, Gladman DD. Factors explaining the discrepancy between physician and patient global assessment of joint and skin disease activity in psoriatic arthritis patients. Arthritis Care Res (Hoboken). 2015;67(2):264-72 https://doi.org/10.1002/a cr.22401.

30. Desthieux C, Hermet A, Granger B, Fautrel B, Gossec L. Patient-physician discordance in global assessment in rheumatoid arthritis: a systematic literature review with meta-analysis. Arthritis Care Res (Hoboken). 2016; 68(12):1767-73 https://doi.org/10.1002/acr.22902.

31. Walsh JA, McFadden ML, Morgan MD, Sawitzke AD, Duffin KC, Krueger GG, et al. Work productivity loss and fatigue in psoriatic arthritis. J Rheumatol. 2014;41(8):1670-4 https://doi.org/10.3899/jrheum.140259.

32. Conaghan PG, Alten R, Deodhar A, Sullivan E, Blackburn S, Tian H, et al. Relationship of pain and fatigue with health-related quality of life and work in patients with psoriatic arthritis on TNFi: results of a multi-national realworld study. RMD Open. 2020;6(2):e001240 https://doi.org/10.1136/ rmdopen-2020-001240

33. Ware JE Jr, Sherbourne CD. The MOS 36-item short-form health survey (SF36). I. Conceptual framework and item selection. Med Care. 1992;30(6):47383 https://doi.org/10.1097/00005650-199206000-00002.

34. Belza BL, Henke CJ, Yelin EH, Epstein WV, Gilliss CL. Correlates of fatigue in older adults with rheumatoid arthritis. Nurs Res. 1993;42(2):93-9.

35. Cella D, Yount S, Sorensen M, Chartash E, Sengupta N, Grober J. Validation of the Functional Assessment of Chronic Illness Therapy Fatigue Scale relative to other instrumentation in patients with rheumatoid arthritis. J Rheumatol. 2005;32(5):811-9.

36. Wolfe F, Michaud K, Pincus T. Preliminary evaluation of a visual analog function scale for use in rheumatoid arthritis. J Rheumatol. 2005;32(7):12616.

37. Gladman D, Nash P, Goto H, Birt JA, Lin CY, Orbai AM, et al. Fatigue numeric rating scale validity, discrimination and responder definition in patients with psoriatic arthritis. RMD Open. 2020;6(1):e000928 https://doi.org/10.1136/ rmdopen-2019-000928.

38. Genovese MC, Mease PJ, Thomson GT, Kivitz AJ, Perdok RJ, Weinberg MA, et al. Safety and efficacy of adalimumab in treatment of patients with psoriatic arthritis who had failed disease modifying antirheumatic drug therapy. J Rheumatol. 2007;34(5):1040-50.

39. Gladman DD, Mease PJ, Cifaldi MA, Perdok RJ, Sasso E, Medich J. Adalimumab improves joint-related and skin-related functional impairment in patients with psoriatic arthritis: patient-reported outcomes of the Adalimumab Effectiveness in Psoriatic Arthritis Trial. Ann Rheum Dis. 2007; 66(2):163-8 https://doi.org/10.1136/ard.2006.057901.

40. Gladman D, Fleischmann R, Coteur G, Woltering F, Mease PJ. Effect of certolizumab pegol on multiple facets of psoriatic arthritis as reported by patients: 24-week patient-reported outcome results of a phase III, multicenter study. Arthritis Care Res (Hoboken). 2014;66(7):1085-92 https:// doi.org/10.1002/acr.22256.

41. Ritchlin C, Rahman P, Kavanaugh A, Mclnnes IB, Puig L, Li S, et al. Efficacy and safety of the anti-IL-12/23 p40 monoclonal antibody, ustekinumab, in patients with active psoriatic arthritis despite conventional non-biological and biological anti-tumour necrosis factor therapy: 6-month and 1-year results of the phase 3 , multicentre, double-blind, placebo-controlled, randomised PSUMMIT 2 trial. Ann Rheum Dis. 2014;73(6):990-9 https://doi. org/10.1136/annrheumdis-2013-204655

42. Gossec L, Kvien TK, Conaghan PG, Ostergaard M, Canete J, Gaillez C, et al. Reduction in fatigue in patients with active psoriatic arthritis are sustained over 2 years: long-term results of two phase 3 studies with secukinumab. Ann Rheum Dis. 2016;75(Suppl 2):351.

43. Mclnnes IB, Mease PJ, Ritchlin CT, Rahman P, Gottlieb AB, Kirkham B, et al, Secukinumab sustains improvement in signs and symptoms of psoriatic arthritis: 2 year results from the phase 3 FUTURE 2 study. Rheumatology (Oxford). 2017;56(11):1993-2003 https://doi.org/10.1093/rheumatology/kex3 01.

44. Almeida C, Choy EHS, Hewlett S, Kirwan JR, Cramp F, Chalder T, et al. Biologic interventions for fatigue in rheumatoid arthritis. Cochrane Database Syst Rev. 2016;6:CD008334.

45. Alvarenga-Filho H, Salles M, Hygino J, Ferreira TB, Sacramento PM, Monteiro

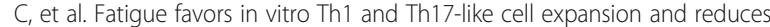
corticoid sensitivity in MS patients. J Neuroimmunol. 2017;303:81-9 https:// doi.org/10.1016/j.jneuroim.2016.12.013.

46. Murphy CA, Langrish CL, Chen Y, Blumenschein W, McClanahan T, Kastelein RA, et al. Divergent pro- and antiinflammatory roles for IL-23 and IL-12 in joint autoimmune inflammation. J Exp Med. 2003;198(12):1951-7 https://doi. org/10.1084/jem.20030896.

47. Skoie IM, Dalen I, Ternowitz T, Jonsson G, Kvivik I, Norheim K, et al. Fatigue in psoriasis: a controlled study. Br J Dermatol. 2017;177(2):505-12 https://doi. org/10.1111/bjd.15375

\section{Publisher's Note}

Springer Nature remains neutral with regard to jurisdictional claims in published maps and institutional affiliations.
Ready to submit your research? Choose BMC and benefit from:

- fast, convenient online submission

- thorough peer review by experienced researchers in your field

- rapid publication on acceptance

- support for research data, including large and complex data types

- gold Open Access which fosters wider collaboration and increased citations

- maximum visibility for your research: over $100 \mathrm{M}$ website views per year

At BMC, research is always in progress.

Learn more biomedcentral.com/submissions 